\title{
A Multi-Objective Planning Framework for Optimal Integration of Distributed Generations
}

\author{
Keshav Pokharel, Student Member, IEEE, Maizura Mokhtar, Member, IEEE, and Joe Howe
}

\begin{abstract}
This paper presents an evolutionary algorithm for analyzing the best mix of distributed generations (DG) in a distribution network. The multi-objective optimization aims at minimizing the total cost of real power generation, line losses and $\mathrm{CO}_{2}$ emissions, and maximizing the benefits from the DG over a 20 years planning horizon. The method assesses the fault current constraint imposed on the distribution network by the existing and new DG in order not to violate the short circuit capacity of existing switchgear. The analysis utilizes one of the highly regarded evolutionary algorithm, the Strength Pareto Evolutionary Algorithm 2 (SPEA2) for multi-objective optimization and MATPOWER for solving the optimal power flow problems.
\end{abstract}

Index Terms-multi-objective evolutionary algorithm, strength pareto evolutionary algorithm 2 , distributed generation, distribution generation planning, three phase symmetrical fault.

\section{INTRODUCTION}

High levels of penetration from distributed generations (DG) are a new challenge for the traditional electrical grid. The term DG is often used to depict a small scale electricity generation connected to low or medium voltage distribution network or nearer to the consumer side [1]. However, different organizations have defined DG differently, and there is no generally accepted definition of DG as yet [1]. In the UK, DG refers to decentralized power units with less than $100 \mathrm{MW}$ capacity connected to the distribution network [1]. DG in general refer, although not confined to, electricity generation technologies such as gas turbines, diesel generators, combined heat and power plants (CHP), wind turbines, solar photovoltaics, micro and small hydro power stations, and energy storage systems (ESS) to some extent.

Although DG represent a small share of the electricity market, they play a key role in situations for applications in which reliability is crucial: as a source of emergency capacity, and as an alternative to expansion of a local network [2]. According to the International Energy Agency (IEA) [2], more DG capacity was ordered in 2000 worldwide than for new nuclear power. The IEA also pointed out that the government policies that favors combined heat and power (CHP) generation and renewable energy technologies are also favoring growth of DG integration [2].

Despite the benefits associated with DG integration in distribution networks, inadequate planning and inappropriate sizing and siting of DG may lead to high power loss and poor

This work was undertaken at the Centre for Energy and Power Management which is partly funded by BAE Systems UK.

All the authors are with the Centre for Energy and Power Management, School of Computing, Engineering and Physical Sciences, University of Central Lancashire, Preston, PR1 2HE, UK, Email: \{kppokharel, mmokhtar, jmhowe\}@uclan.ac.uk. voltage profile [3]. As the integration of DG increases, it is in the best interest of all players involved to allocate DG in an optimal way, such that it will reduce system losses and improve voltage profile.

Various studies have suggested that inadequate selection of DG locations and sizes may result in greater system losses as well as system instability [3],[4]. Optimum selection of DG locations and sizes will result in reduction of system losses, improvement in voltage profiles and betterment of reliability of supply. It can also relieve pressure on transmission and distribution ( $\mathrm{T} \& \mathrm{D}$ ) network and can defer new capital intensive investments [3],[5].

This paper proposes a suitable planning and optimization technique to integrate renewable and non-renewable DG in a distribution network with existing generation. The main target will be to find the optimal size and position of both renewable and non-renewable DG in the distribution network. The tool used is the Strength Pareto Evolution Algorithm 2 (SPEA2). SPEA2, a type of multi-objective evolutionary algorithm (MOEA) chosen because of its suitability for optimizing the different types of stochastic and controllable DG simultaneously [5]. SPEA2 is mentioned to out-perform other MOEA techniques, for example the Non Sorting Genetic Algorithm II (NSGA-II) [5]-[7]. This optimization tool can provide essential support for decision makers concerning the choice of sizing and positioning of DG without imposing too much pressure on reliability considering the fault contributions from the generators.

Inclusion of DG generally results in higher levels of fault currents. The fault contribution from a single small DG unit may not be large, however, the aggregate contributions of many DG units can alter the short circuit levels enough to cause fuse-breaker mis-coordination. This could affect the reliability and safety of the distribution system. With the addition of new DG units to the system, the fault current may become large enough to exceed the fault current capacity of switchgear of the system. Therefore, three phase symmetrical short circuit analysis has been conducted for each optimal configuration of the DG in order to make sure that the total fault current does not exceed the switchgear short circuit capacity.

This paper is organized into five sections. Section II describes the various aspects of DG planning process. Section III focuses on the SPEA2 being used for the optimization work. Section IV presents the broad methodology and problem formulation for the DG integration analysis; and finally conclusions are presented in Section V. 


\section{DG Planning Process}

The main goals of the DG planning process are to identify and evaluate alternatives, for example the types of DG available, their sizes and the possible nodes to install them. The MOEA planning framework is able to provide the best configuration of DG in a distribution network that meet a varied number of objectives and constraints. The objectives and constraints are presented in Sections III-B and III-C respectively. The MOEA framework will provide a better understand of DG integration by finding several Pareto optimal DG configurations, and analyzing the relationship between multiple objectives of DG integration.

\section{A. Strength Pareto Evolution Algorithm 2 (SPEA2)}

SPEA2 is a highly regarded MOEA used to help solve a wide range of conflicting power system problems [5]. SPEA2 performs its functionality based on evolutionary theory and aims to find the most optimal (genetic) solution(s) through the improvement of genes and the survival of the fittest. SPEA2 produces the final optimal solutions in the form of a Paretooptimal front [5],[7]. The key steps in MOEA involve [8]:

1) the choice of presentation and coding techniques for the solution or the solution vector (Section III-A),

2) the formulation of the fitness objectives and constraints requirements for the problem (Sections III-B and III-C),

3) the evaluation the fitness objectives for each solution vector and the constraint functions, and

4) the application of the genetic operators, i.e. reproduction, crossover and mutation iteratively (per generation).

MOEA evolves the solution vectors until the optimal Paretooptimal solution is obtained [8]. The evolved Pareto-optimal solution will offer the network planners an effective solution to multi-objective network expansion problems incorporating DG integration.

\section{B. MATPOWER}

The analysis utilizes MATPOWER [9] that conducts the optimal power flow (OPF) calculations used to evaluate the attributes of the distribution network being considered. MATPOWER is an open source MATLAB power network simulation package developed by Zimmerman et al. for solving power flow and optimal power flow problems [9]. OPF formulation is used to control the active DG power within the network operational constraints (voltage/line loading).

\section{Fault Constraints}

The conventional OPF method does not consider the constraints imposed by lines, generators and transformers on expected fault levels. Therefore, each optimal DG configuration obtained after the MOEA execution is tested for expected fault levels on the system. Those that violate the fault level are discarded. The process continues iteratively until all the optimal solutions satisfy the defined fault level constraints. It is assumed that that only one short circuit fault occurs at each node in the system for simplicity.

The DG planning framework has been demonstrated with IEEE 14 bus network (details in [10]).

\section{Methodology and Problem Formulation}

The IEEE 14 bus test network is used for the demonstration of the approach. Existing DG production profiles, as obtained in secondary literatures are considered to calculate the average yearly capacity factor of the DG units considered. The deterministic OPF are performed in succession for each possible condition of the power network (DG production/demand) for each year; and the network variables resulting from the OPF (voltage, power flows) permit the calculation of other electrical attributes (e.g. line losses, power generation from existing generators), environmental attribute (load $\mathrm{CO}_{2}$ factor), and economic attributes (e.g. DG benefits, total cost) for the entire planning period of 20 years. The process is repeated for a number of simulations or until a convergence condition based on a required degree of precision is achieved.

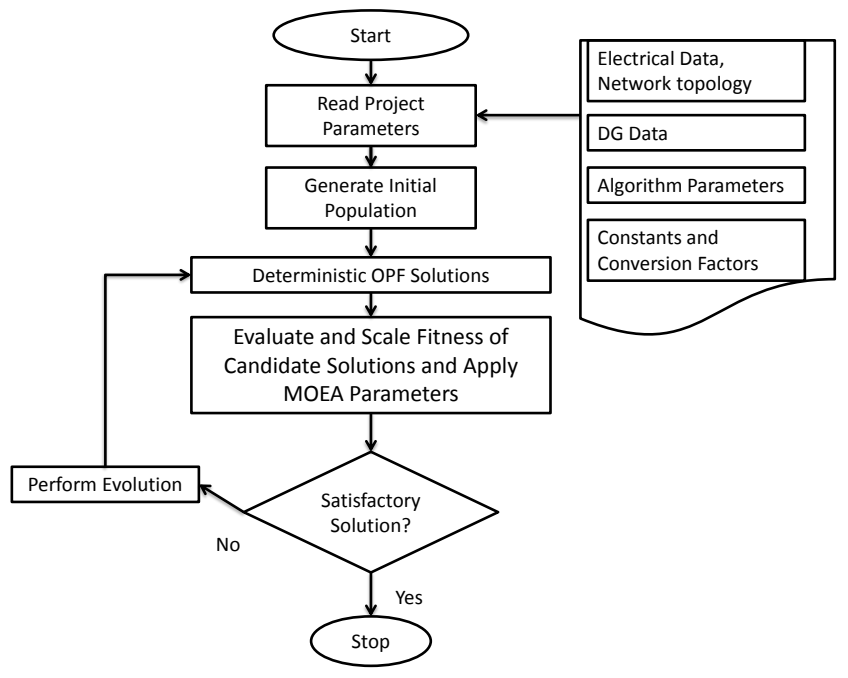

Fig. 1. Implementation of the Optimization Algorithm

SPEA2 is used to optimize the placement and size of the DG integration using three key steps of MOEA listed in Section II-A.

\section{A. Coding of the Solution Vector}

The solution vector $S_{v}$ consists of four control variables (or genes) for each DG integrated in the distribution network. $S_{v}$ is coded using (1).

$$
X=[x, z, p, v] ; X \in S_{v}
$$

$x, z, p$ and $v$ represent the location, size, node power and node voltage. Real number coding has been used for all the four control variables so that each $S_{v}$ consist of a string of real numbers, whose length varies depending on the total number of DG considered.

\section{B. Fitness Objectives Formalization and Evaluation}

The multi objectives framework proposed considers the practical constraints in the choice of the rating and positioning of DG. The objectives considered are the:

- minimization of real power generation costs, $f(c)$. 
- minimization of system losses, $f(p)$.

- minimization carbon emissions, $f(e)$.

- maximization of the total annual benefits from DG, $f(b)$.

The multi objectives are formulated as:

$$
\begin{gathered}
f(c)=\sum_{t=1}^{n_{t}} \sum_{g=1}^{n_{g}} L C O E_{g}^{t} \mathbf{x} E_{g}^{t} \\
f(p)=\sum_{t=1}^{n_{t}} \sum_{l=1}^{n_{l}} \text { Linelosses }_{l}^{t} \\
f(e)=\frac{\sum_{t=1}^{n_{t}} L C O_{2}^{t}}{n_{t}} \\
f(b)=\sum_{t=1}^{n_{t}} \sum_{g=1}^{n_{g}} D G \text { Benefits }{ }_{g}^{t} \\
E_{g}=I C_{g} \mathbf{x} C F_{g} \mathbf{x} 8760
\end{gathered}
$$

$n_{t}$ is number of years in the planning horizon. $n_{g}$ and $n_{l}$ are the number of DG options and branches respectively. $L C O E_{g}^{t}$ and $E_{g}^{t}$ are the levelised cost of real power generation and the annual energy output from a DG in year t. $L C O_{2}^{t}$ is the load $\mathrm{CO}_{2}$ factor in $\mathrm{g}-\mathrm{CO}_{2} / \mathrm{kWh}$ in year $t$ (to be explained in Sec. III-B2). $I C_{g}$ and $C F_{g}$ are the installed capacity and capacity factor of a DG, assumed to be same in each year.

Equations (2) - (5) are the fitness objectives representing minimization of total levelized cost of real power generation, total line losses, environmental attribute, and maximization of total benefits from the DG. Equations (4) and (5) help justify the integration of the renewable DG to the distribution network considering their benefits and environmental aspects.

1) Economic Attributes: The economic attributes consider the time value of money. In this paper, three attributes have been considered: (i) annualized cost of DG ( $£ /$ year), (ii) levelized cost of DG ( $£ / \mathrm{kWh})$ and (iii) annualized DG benefits ( $£ /$ year). The levelized cost of energy ( $L C O E)$ is the most common term used to measure the electrical power generation costs, and is widely used to compare the generation cost from different sources.

The calculation of economical attributes consider the capital cost of installation and the operation and maintenance $(\mathrm{O}$ $\&$ M) costs. One of the most common methods used to translate these attributes into common comparable values, is to convert all the costs and benefits into annuities (equal annual values) considering the time value of money. The costs of DG considered are levelized costs of real power generation $(L C O E)$ in $£ / \mathrm{kWh}$ considering both the fixed installation cost at the beginning of the evaluation period (year zero) and the variable costs occurring annually throughout the planning horizon. Although the $\mathrm{O} \& \mathrm{M}$ costs vary from year to year in practice, for simplicity they have been considered constant throughout the planning period.
2) Environmental Attribute: The environmental attribute is measured in terms of the $\mathrm{CO}_{2}$ emission. Concept of Load $\mathrm{CO}_{2}$ factor $\left(\mathrm{LCO}_{2}\right.$ factor) as coined in [11] is used to measure the environmental attribute in terms of $\mathrm{CO}_{2}$ emission. Load $\mathrm{CO}_{2}$ indicates the $\mathrm{CO}_{2}$ emission resulting from energy usage (and generation) of the DG. The minimization of the load $\mathrm{CO}_{2}$ emission will result in the best low-carbon mix of DG. Annual value of $\mathrm{LCO}_{2}$ is given by:

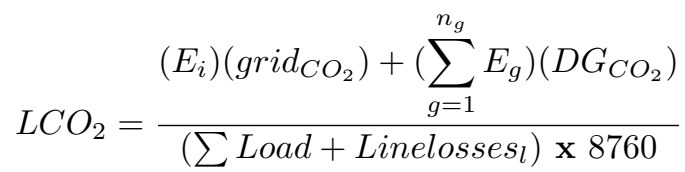

Average value of the annual $L C \mathrm{O}_{2}$ over the planning horizon as per (4) is considered as an objective for optimization. $\mathrm{LCO}_{2}$ depends on the total energy imported from the grid (or energy generation from existing generators in the network), $E_{i}$ and the DG output, $E_{g} \cdot g_{r i d} \mathrm{CO}_{2}$ and $D_{\mathrm{CO}_{2}}$ are the average $\mathrm{CO}_{2}$ emission values of the grid (currently set at $\left.539 \mathrm{~g}-\mathrm{CO}_{2} / \mathrm{kWh}[12]\right)$ and the DG respectively. This factor is assumed constant and not affected by DG penetration. $D G_{\mathrm{CO}_{2}}$ is the ratio of the total $\mathrm{CO}_{2}$ emission of a DG over the total energy generation and is given by:

$$
D G_{C O_{2}}=\frac{E F_{g} \mathbf{x} E_{g}}{\sum_{g=1}^{n_{g}} E_{g}}
$$

Where $E F_{g}$ is the emission factor (in $\mathrm{g}-\mathrm{CO}_{2} / \mathrm{kWh}$ ) of a DG. The denominator term in (8) is the total energy generation from all DG in a year.

3) The benefits of DG: A complete financial evaluation of a DG investment project requires a detailed analysis of the benefits and costs over the planning period. Net benefits are calculated by deducting the annual costs from the annual revenues that are obtained from the DG installations. Two sources of revenue considered are (i) the revenues from the direct sale of energy (energy revenues) and (ii) the incentives received from producing renewable energy including CHP (e.g. FIT). The feed-in-tariff (FIT) is a scheme that pays the people for creating their own "green" electricity. The main benefit of FIT is the generation tariff, which is paid for every kilowatt hour of electricity produced. The amount paid per hour is usually determined by the type of technology and the size of the system installed [16]. The total annual benefit from the DG is calculated using (9).

$$
D G_{\text {benefits }}=\sum_{i=1}^{n_{g}} C_{E} E_{g}+\sum_{i=1}^{n_{d}} F I T_{d} D G_{d}-f(c)
$$

$F I T_{d}$ and $D G_{d}$ are the governments green benefits for a entitled renewable DG (including CHP) and the annual energy output from that DG respectively (indexed by the letter $d$ ).

\section{Constraint Functions}

The constraint functions (10)-(16) specify the boundaries of the network and attributes being considered. MATPOWER 
validates each of the given generator combination (as per the chromosome structure) against constraints (10)-(15) to ensure networks conditions are met as per the constraints specified. The resulting flow parameters and network voltages are used to calculate attributes to be fed to the MOEA algorithm. The optimal solution obtained is validated with fault current constraint (16) in order to ensure the optimal DG configurations selected obey the fault current constraint. Fault current constraint is discussed in Sec. III-C1.

$$
\begin{gathered}
\theta_{b(\min )} \leq \theta_{b} \leq \theta_{b(\max )}, b=1, \ldots, n_{b} \\
V_{b(\min )} \leq V_{b} \leq V_{b(\max )}, b=1, \ldots, n_{b} \\
P_{g(\min )} \leq P_{g} \leq P_{g(\max )}, g=1, \ldots, n_{g} \\
Q_{g(\min )} \leq Q_{g} \leq Q_{g(\max )}, g=1, \ldots, n_{g} \\
S_{l(\min )} \leq S_{l} \leq S_{l(\max )}, l=1, \ldots, n_{l} \\
n_{g}<n_{g(\max )}, g=1, \ldots, n_{g} \\
F L_{b}<S S C_{b}
\end{gathered}
$$

$\theta$ and $V$ refer to the voltage angle and magnitude. $P, Q$ and $S$ refer to the real and reactive powers and the branch thermal limits. The indexes $b, g, l, \max$ and min represent the node (bus), DG type, line (branch), maximum value and minimum value respectively. Likewise, $F L_{b}$ and $S S C_{b}$ denote the fault level and short circuit fault capacity of switchgear at each bus respectively.

Distributed generators usually provide energy with a unitary power factor ( $\mathrm{pf}$ ). The analysis conducted only consider the cost of real power generation. However, the reactive power constraint in (13) ensure that the reactive power of each generation is obeyed to maintain acceptable voltage limits and the uniform power factor.

1) Inclusion of fault levels constraints: Fault levels are usually a concern with large penetration of DG in distribution networks. DG, in general, increase the fault currents and therefore prompt the requirement for larger switchgear equipment [11],[13]. Incorporation of the fault constraints may limit the DG integration but help find a reliable system with less fault currents.

The fault level calculation is included by applying a three phase short circuit at each node in the system. The three-phase short circuit fault is chosen because it gives the most severe fault level and is used in specifying switchgear rupturing capacity [13]. The inclusion of this fault level calculation may help ensure that the switchgear in the network considered is capable of dealing with the expected faults currents.

The short circuit calculations are executed using standard three phase short circuit calculation procedure given in [13] and [15]. OPF formulations usually do not consider the constraints imposed by the protection equipment on expected fault levels. The OPF formulations may involve the formation of $\mathrm{Y}$ bus matrix, $Y_{\text {bus }}$ (or $\mathrm{Z}$ bus matrix, $Z_{\text {bus }}$ ) considering the steady state impedances of the system components (e.g. lines, transformers, generators, motors). $\mathrm{Y}$ bus matrix is a $n_{b} \mathrm{x} n_{b}$ matrix describing a power system with $n_{b}$ buses. It represents the nodal admittance of the buses in a power system. $\mathrm{Z}$ bus matrix is the inverse of the $\mathrm{Y}$ bus matrix $\left(Z_{b u s}=1 / Y_{\text {bus }}\right)$. The bus currents $\left(I_{b u s}\right)$ and voltages $\left(V_{b u s}\right)$ are related by general relationship: $I_{b u s}=Y_{\text {bus }} \times V_{\text {bus }}$ and $V_{b u s}=Z_{b u s} \times I_{b u s}$.

Calculation of fault current envisage the formation of $Y_{b u s}$ (or $Z_{b u s}$ ) considering the different time variant reactances (sub-transient, transient, steady state) of the generators. However consideration of all these reactances is beyond the scope of this paper and only sub-transient reactance of generators has been considered for the three phase symmetrical fault analysis.

For each configuration of the DG represented by a chromosome, a $Y_{\text {bus }}$ for the system is built considering the resistances and reactances of the system component. Then the three-phase short circuit fault current is calculated as the ratio of prefault voltage and the per unit value of the impedance from the source of the voltage to the point of the fault (17).

$$
\text { Fault Current }{ }_{f}^{b}=\frac{V_{0}^{b}}{\left(Z_{b, b}+Z_{f}\right)}
$$

The left hand term in (17) is the per unit fault current at bus b. $V_{0}^{b}$ is the pre-fault voltage at bus $\mathrm{b}$ (assumed to be $1 \mathrm{pu}$ for the fault analysis part). $Z_{b, b}$ and $Z_{f}$ are fault bus impedance at bus $b$ (diagonal elements of fault bus impedance) and the fault path impedance respectively. In this paper, three phase short circuit faults are considered at each bus with fault path impedance assumed to be zero.

Three phase fault level calculation for a large network involve some modifications of the input information so that machines are represented by the appropriate reactances [15]. The generators are represented by their no load voltages in series with the sub-transient reactances. To calculate the short circuit current to ground at a given location (node) in the network, the network input impedance at this node is the factor that determines the magnitude of this current. Assuming the pre-fault voltage equal to nominal voltage (1 pu), fault currents are calculated using (18).

$$
F L(p u)=I_{f}(p u)=\frac{1}{Z(p u)}
$$

The fault current column vector will have zero elements for all buses except the faulted bus.

The fault current calculated at each bus is tested for capacity adequacy of the system in the form of short circuit current rating of the switchgear. Generalized short circuit capacity level of $50 \mathrm{kA}$ rms (the standard UK norms) has been considered for this purpose. However, switchgear can be tested for capacity adequacy in terms of fault MVA capacity. But due to the lack of benchmark for capacity adequacy at different voltage levels of the IEEE 14 bus system (13.8, 18 and 69 $\mathrm{kV}$ ), the generalized fault current capacity of $50 \mathrm{kA} \mathrm{rms}$ is used for the ease of analysis.

The fault constraint handling routine is illustrated in Fig. 2. 
TABLE I

DG DATA

\begin{tabular}{|c|c|c|c|c|c|c|c|c|}
\hline Type & $\mathrm{P}_{g}(\mathrm{MW})$ & $\begin{array}{l}\mathrm{P}_{g} \text { (Max.) } \\
(\mathrm{MW})\end{array}$ & $\begin{array}{l}\mathrm{P}_{g} \text { (Min.) } \\
(\mathrm{MW})\end{array}$ & $\begin{array}{l}\mathrm{Q}_{g} \quad(\mathrm{Max} .) \\
\text { (MVAr) }\end{array}$ & $\begin{array}{l}\mathrm{Q}_{g} \quad \text { (Min.) } \\
\text { (MVAr) }\end{array}$ & $\begin{array}{l}\text { Capacity Fac- } \\
\text { tors }\end{array}$ & $\begin{array}{l}\text { Environmental } \\
\text { Emission Factors } \\
\left(\mathrm{kg}-\mathrm{CO}_{2} / \mathrm{kWh}\right)\end{array}$ & $\begin{array}{l}\text { FIT Rate } \\
(£ / \mathrm{kWh}) \\
{[16]}\end{array}$ \\
\hline Diesel & 0.06 & 0.06 & 0 & 0.06 & -0.06 & 0.9 & $0.88[18]$ & - \\
\hline Gas & 0.055 & 0.055 & 0 & 0.055 & -0.055 & 0.9 & $0.326[12]$ & - \\
\hline SPV & 0.05 & 0.05 & 0 & 0.05 & -0.05 & $0.1151[21]$ & $0.045[18]$ & 0.329 \\
\hline WT & 0.05 & 0.05 & 0 & 0.05 & -0.05 & $0.2712[21]$ & $0.011[18]]$ & 0.253 \\
\hline
\end{tabular}

TABLE II

LCOE CALCULATIONS

\begin{tabular}{|c|c|c|c|c|c|}
\hline & Diesel & GT & $\mathrm{CHP}^{a}$ & SPV & WT \\
\hline Rated Power $(\mathrm{kW}), \mathrm{A}$ & 60 & 55 & 54 & 50 & 50 \\
\hline Capacity Factor, B & 0.9 & 0.9 & 0.6375 & 0.11 & 0.27 \\
\hline Installation Cost $(£ / \mathrm{kW}), \mathrm{C}$ & $864^{b}$ & $866^{b}$ & - & 3339 [24] & 3762 [24] \\
\hline Total Installation Cost $(£), \mathrm{D}=\mathrm{AxC}$ & 51840 & 47630 & $65700[25]$ & 166950 & 188100 \\
\hline Heat to Power Ratio, E & - & - & $1.8[25]$ & - & - \\
\hline Installation Cost attributed to Electricity $(£), \mathrm{F}=\mathrm{D} /(\mathrm{E}+1)$ & 51840 & 47630 & 23464 & 166950 & 188100 \\
\hline Electrical Energy $(\mathrm{kWh} / \mathrm{yr}), \mathrm{G}=8760 \times \mathrm{x} \times \mathrm{B}$ & 473040 & 433620 & 301563 & 48180 & 118260 \\
\hline Annuity Factor, $\mathrm{H}^{c}$ & 10.59 & 10.59 & 10.59 & 10.59 & 10.59 \\
\hline Annuity of Installation Cost, $\mathrm{I}=\mathrm{F} / \mathrm{H}$ & 4893.33 & 4495.94 & 2214.86 & 15758.9 & 17755.31 \\
\hline Maintenance Cost (£/year), J & $1060^{d}$ & $971.67^{d}$ & $4250[25]$ & 1240 [24] & 2070 [24] \\
\hline Maintenance Cost attributed to Electricity ( $£ /$ year), $\mathrm{K}=\mathrm{J} /(\mathrm{E}+1)$ & 1060 & 971.67 & 1517.86 & 1240 & 2070 \\
\hline O\&M (Fuel) Cost $(£ / \mathrm{kWh}), \mathrm{L}$ & $0.14[26]$ & $0.027[27]$ & $0.027[27]$ & 0 & 0 \\
\hline O\&M (Fuel) Cost ( $£ /$ year), $\mathrm{M}=\mathrm{GxL}$ & 63860.4 & 11707.74 & 8142.2 & 0 & 0 \\
\hline Total Annual Cost $(£), \mathrm{N}=\mathrm{I}+\mathrm{K}+\mathrm{M}$ & 69813.73 & 17175.34 & 11874.92 & 16998.9 & 19825.31 \\
\hline LCOE $(£ / \mathrm{kWh}), \mathrm{O}=\mathrm{N} / \mathrm{G}$ & 0.1476 & 0.0396 & 0.0394 & 0.3528 & 0.1676 \\
\hline
\end{tabular}

${ }^{a}$ The "heat to power ratio" of the CHP, $n$, is mainly used to apportion the total cost and environmental parameters of the CHP proportionately to the electrical energy generation part as per equation: Attribute $\mathrm{CHP}_{P}($ Electrical $)=\left(\right.$ Total Attribute $\left._{C H P}\right) /(n+1)$.

${ }^{b}$ As per [22] with costs in US \$ (2010 price) assumed to be costs in $£$ (2012 price).

${ }^{c}$ At discount rate of $7 \%$ and 20 years period.

${ }^{d}$ As per [22] with cost in US $\$$ converted to $£$ (by dividing by 1.5 ).

\section{Test System}

The block diagram of IEEE 14 bus test network is shown in Fig. 3. MATPOWER is used to validate each possible generation condition of the network represented by a chromosome and perform OPF to calculate the electrical variables such as the voltages and line losses. These variables have been used to calculate other planning attributes, such as the technical,

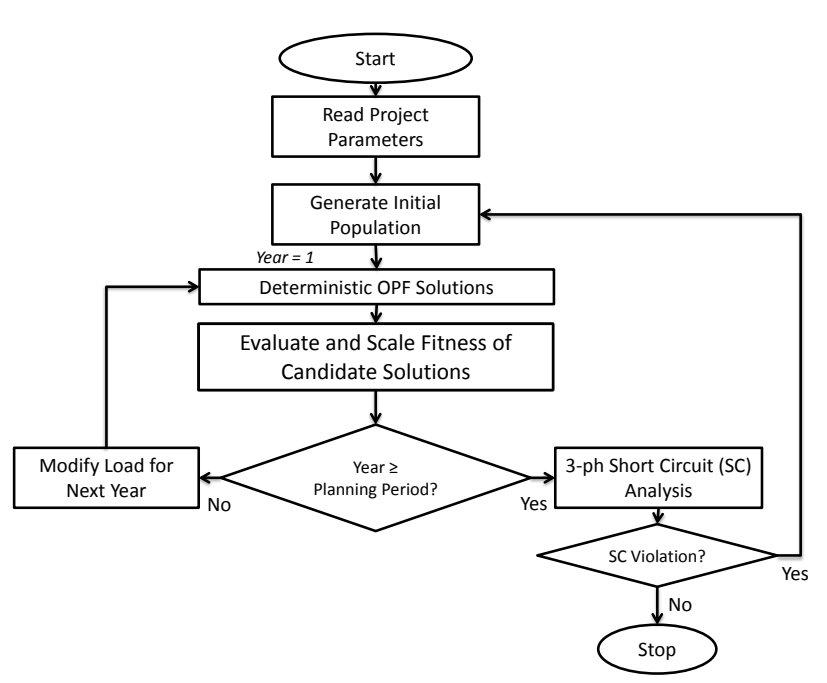

Fig. 2. Fault Constraint Handling economic and environmental attributes which in turn are fed to the SPEA2 to evaluate the objectives values. The IEEE 14 bus network is modified to facilitate the MATPOWER OPF validation of each generation option represented by a chromosome. This is achieved by increasing the cost parameters of existing generators by 10 .

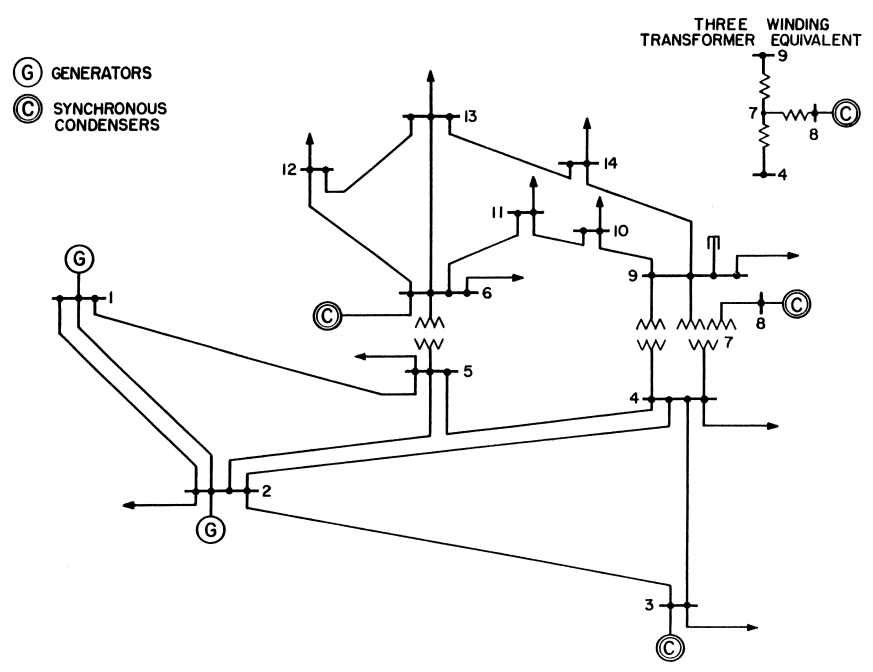

Fig. 3. IEEE 14 Bus Test Network [10]

A moderate load growth of $2 \%$ per year has been considered for the analysis resulting in $1.456 \%$ growth during the planning 


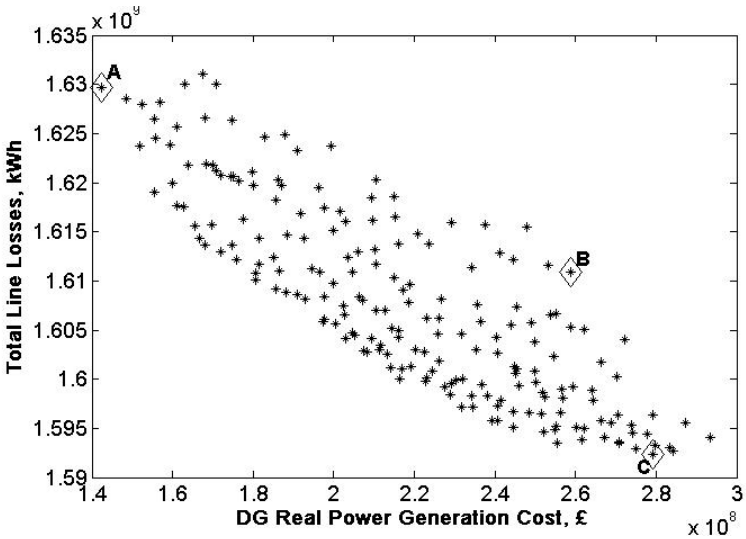

(a) Total Line Losses Vs DG Real Power Generation Cost: Total line losses decreases linearly with increase in the DG costs. This is because more DG are selected nearer to the loads.

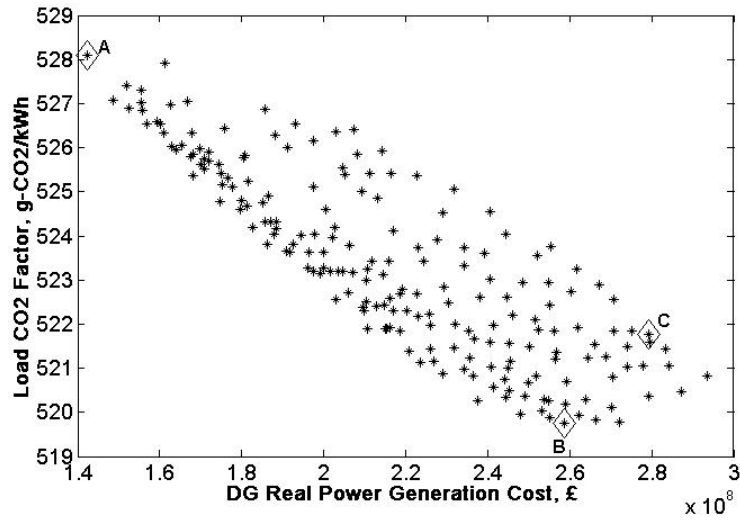

(b) Load $\mathrm{CO}_{2}$ Factor Vs DG Real Power Generation Cost: Selection of higher number of DG (except diesel generators) decreases the load emission factor from A to B. However, higher number of diesel generators (with high emission factor) and lesser number of WT causes the load emission factor to increase slightly from B to C.

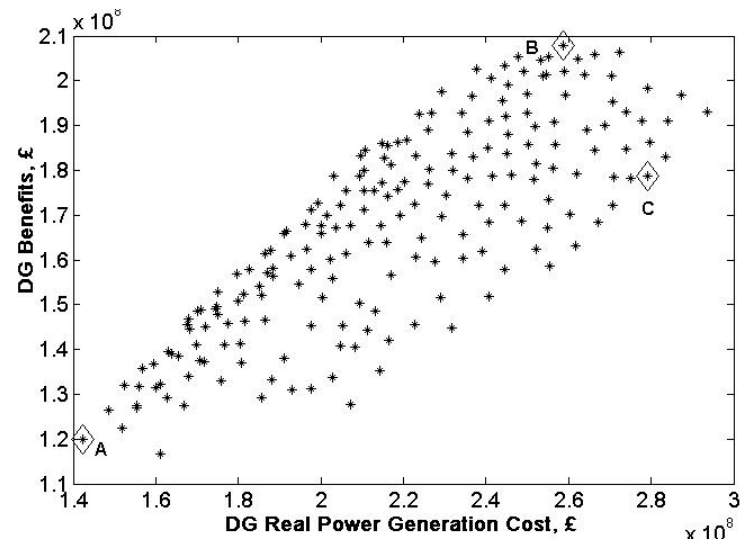

(c) DG Benefits Vs DG Real Power Generation Cost: Similar to Fig. (b) above, selection of higher numbers of DG (except diesel generators) increases the total benefit from A to B. However, high number of expensive diesel generators and less number of financially attractive WT causes the total benefits to decrease slightly from B to $\mathrm{C}$.

Fig. 4. Plots of Optimal Solutions horizon (from $259 \mathrm{MW}$ and $78 \mathrm{MVAr}$ in year 1 to $377 \mathrm{MW}$ and 107 MVAr respectively in year 20).

\section{E. DG Data}

Five different types of DG are considered for analysis: diesel generator, gas turbine (GT), combined heat and power plant $(\mathrm{CPH})$, solar photovoltaics (SPV) and wind turbine (WT). The technical parameters, constants and conversion factors of these generators are listed in Table I. The financial parameters and LCOE calculations are presented in Table II. Among the DG considered, diesel generator is most expensive option while the WT is the most beneficiary considering the income through the FIT.

TABLE III

SUBTRANSIENT REACTANCES

\begin{tabular}{|c|c|c||c|c|c|c|}
\hline \multicolumn{3}{|c||}{ Existing Generators $^{a}$} & \multicolumn{4}{c|}{ DG $^{b}$} \\
\hline Bus & $\mathrm{r}(\mathrm{pu})$ & $\mathrm{x}(\mathrm{pu})$ & Bus & DG Type & $\mathrm{r}(\mathrm{pu})$ & $\mathrm{x}(\mathrm{pu})$ \\
\hline 1 & 0 & 0.03740 & - & Diesel & 0 & 175 \\
\hline 2 & 0.005167 & 0.2167 & - & GT & 0 & 175 \\
\hline 3 & 0.005167 & 0.2167 & - & CHP & 0 & 175 \\
\hline 6 & 0.0056 & 0.48 & - & SPV & 0 & 175 \\
\hline 8 & 0.0056 & 0.48 & - & WT & 0 & 175 \\
\hline
\end{tabular}

${ }^{a}$ Source: [17], with values converted to the system base (100 MVA) from the corresponding generator bases.

${ }^{b}$ Average value of $17.5 \%$ sub-transient reactance as per [28] has been considered for each DG on generator base of $0.1 \mathrm{MVA}$ with values converted to system base of 100 MVA as per (19).

The special case of assessment of costs and environmental attributes for CHP is presented as a footnote in the Table II. For a CHP, electricity is a by-product of heat generation. Therefore cost and environmental parameters of CHPs are to be apportioned to the electricity generation using the "heat to power ratio" of the CHP [20].

Table III lists the sub-transient reactances of the existing generators and DG considered for the analysis. The machine resistance $(r)$ and reactance $(x)$ data have been converted from their respective MVA base to system MVA base (100 MVA) using (19).

$$
Z_{\text {system }}=Z_{g} \mathrm{x} \frac{M V A_{\text {system }}}{M V A_{g}}
$$

TABLE IV

OPTIMAL SOLUTIONS

\begin{tabular}{|l|l|l|l|}
\hline \multirow{2}{*}{ DG Units } & $\begin{array}{l}\text { Case A } \\
\text { (Lowest DG } \\
\text { Cost) }\end{array}$ & $\begin{array}{l}\text { Case } \\
\text { (Lowest } \\
\text { LCO2) }\end{array}$ & $\begin{array}{l}\text { Case C } \\
\text { (Lowest Line } \\
\text { Losses) }\end{array}$ \\
\cline { 2 - 4 } & $\begin{array}{l}\text { Total No. Se- } \\
\text { lected }\end{array}$ & $\begin{array}{l}\text { Total No. Se- } \\
\text { lected }\end{array}$ & $\begin{array}{l}\text { Total No. Se- } \\
\text { lected }\end{array}$ \\
\hline Diesel & 0 & 2 & 18 \\
GT & 101 & 226 & 211 \\
CHP & 149 & 220 & 209 \\
SPV & 42 & 97 & 155 \\
WT & 144 & 230 & 193 \\
\hline \hline $\begin{array}{l}\text { Average Cost of DG } \\
\text { Electricity (£/kWh) }\end{array}$ & 0.0659 & 0.0655 & 0.0721 \\
\hline $\begin{array}{l}\text { Total DG Benefits } \\
\left(£ \times 10^{6}\right)\end{array}$ & 120 & 208 & 179 \\
\hline
\end{tabular}


TABLE V

FAULT CURRENTS

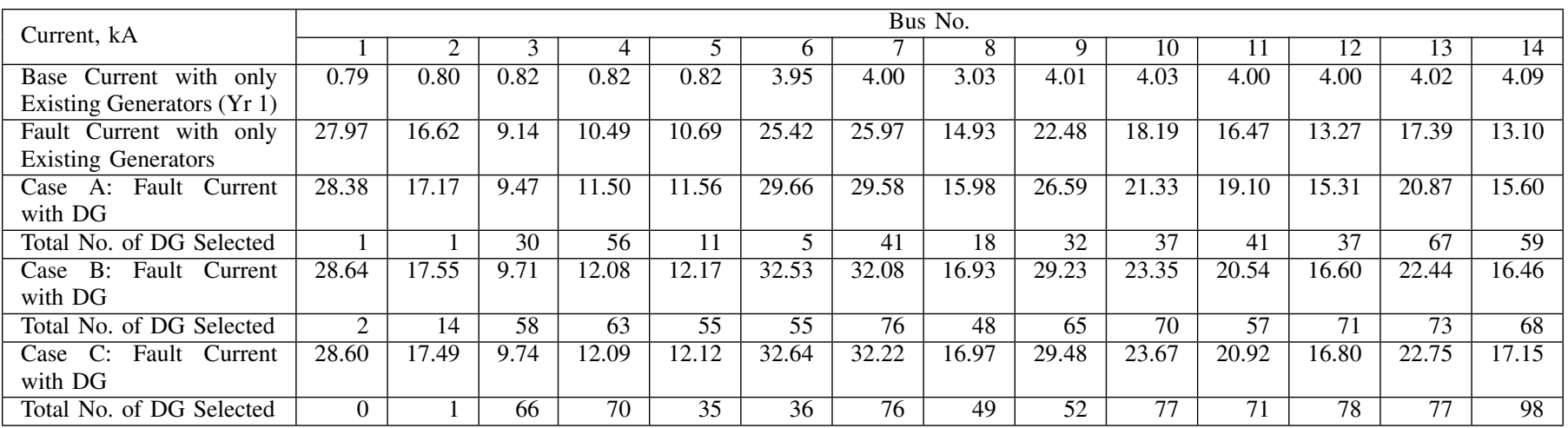

\section{Results AND Discussions}

The SPEA2 parameters used for the analysis are:

- Population and archive sizes $=200$.

- Number of generations $=200$.

- Crossover rate and type $=0.85$, Uniform.

- Mutation rate $=1 / 70(0.01423)$.

The analysis is conducted with peak loads with unity power factor for a period of 20 years. The voltage constraint in the network is deterministic and is limited to $+/-6 \%$ of the nominal voltage $(1 \mathrm{pu})$. Average electricity tariff of 0.075 $£ / \mathrm{kWh}$ is used for benefit calculations.

Fig. 4 (a), (b) and (c) show plots of the different objectives for the optimal solutions obtained after 200 generations. For illustration, three cases: (A) solution with lowest cost of real power generation, (B) solution with lowest $\mathrm{LCO}_{2}$ and (C) solution with lowest total line losses are chosen to facilitate the description of Pareto fronts. The solutions shown in Fig. 4 produce conflicting scenarios between the objective functions. If all the objectives are equally important, none of these solutions is the best with respect to all the objectives. However, these sets of solutions can help the system planner to evaluate the solutions considering their required criteria.

Table IV presents some of the characteristics of the optimal solutions $\mathrm{A}, \mathrm{B}$ and $\mathrm{C}$, where the total number of DG units selected for each case along with some other attributes are presented. It indicates that the total DG cost is the highest for Case $\mathrm{C}$ resulting in highest average cost of DG electricity $(£ / \mathrm{kWh})$. Likewise, selection of less number of expensive diesel generators and SPV, and high number of WT (which yields more green benefits) causes total benefits to be higher in Case B compared to Case C. The average cost of electricity from the DG is highest for Case $\mathrm{C}$, which is mainly due to comparatively high number of expensive SPV selected.

It is seen that with given cost structures and technical parameters, CHP with higher capacity factor and lower generation cost (Table II) is normally the most attractive option for energy generation. This is closely followed by the WT. Diesel generator is the least attractive option for all cases.

Comparing Fig. 4 (a) to (c), some important characteristics of Pareto fronts can be recognized, with two extremes of the Pareto front. Solution A represents almost the "do nothing" scenario whereas Solutions B and C correspond to the selection of higher number of DG in general. The Pareto front A to B in Fig. 4 (b) corresponds to gradual decrease in $\mathrm{CO}_{2}$ emission with higher investments in the renewable DG and lower investments in diesel generators. Hence, the set of solutions represented by the Pareto-front in the region around Cases B and C will be of interest from carbon saving perspectives.

Table V shows some of the attributes of the fault analysis carried out for the optimal solutions obtained. The IEEE 14 bus test system contributes significant fault current under the three phase symmetrical short circuit condition, with the most severe effect being at bus 1 with the largest existing generator.

However due to the small capacity of DG (DG rating of 0.1 MVA in comparison to the 100 MVA base of the system), the increase in fault current is small. This is evident in Table V.

Comparing the three cases A, B and C, Case A results in slightly less increase in the fault current than Cases B and C. This is due to the relatively less number of DG integrated. The maximum increment in fault current due to the DG integration compared to the base case is only about $7 \mathrm{kA}$ for Case B at bus 9 (about 30\% increase) which is small compared to switchgear capacity of 50kA considered. However it may not be the case with comparatively bigger DG. It is essential to consider the expected rise of fault current under short circuit conditions while considering the integration of DG in a distribution network.

The MOEA is capable of evolving the solutions as per the short circuit contributions from the DG, and is able to validate different configurations of DG represented by its chromosomes, considering DG fault current contributions.

\section{CONCLUSIONS}

The paper proposed an efficient MOEA/SPEA2 based multiperiod framework for distribution generation planning that optimizes size and location of distributed generations. The method will allow all players/network operators to understand the trade-off relationship of different objectives being considered. The economic benefits of deploying various renewables and non-renewables DG systems can also be exploited through the proposed method. The framework is able to find the optimal solution for the DG allocation problem subject to both network constraints and restrictions imposed by switchgear 
fault ratings. However, the SPEA2 approach being considered needs ascertaining and evaluating various internal parameters and system attributes that are essential for evolving the solution vectors towards the Pareto-optimal front.

It is seen that the fault current contributions from new DG depend on the voltage levels at different buses at which the DG are connected, and to the sizes of the DG proportional to the system size. Small sizes of DG may not result in significant increase of fault current under the short circuit condition. Nevertheless, the approach followed can be effectively used to evaluate sizing and locations of DG of bigger sizes, in which the fault current contributions could be higher.

\section{REFERENCES}

[1] T. Ackermann, G. Andersson, and L. Soder, "Distributed generation: a definition", Electric Power Systems Research 57, no. 3, pp. 195-204, 2001.

[2] IEA, "Distributed Generation in Liberalised Electricity Markets," International Energy Agency, 2002.

[3] T. Griffin, K. Tomsovic, D. Secrest, and A. Law, "Placement of dispersed generation systems for reduced losses", Proc. of the 33rd Annual Hawaii International Conference System Sciences 2000, pp. 9, 2000.

[4] J. A. P. Lopes, N. Hatziargyriou, J. Mutale, P. Djapic, and N. Jenkins, "Integrating distributed generation into electric power systems: A review of drivers, challenges and opportunities," Electric Power Systems Research, vol. 77, no. 9, pp. 1189-1203, 2007.

[5] A. Alarcon-Rodriguez, G. Ault, and S. Galloway, "Multi-objective planning of distributed energy resources: A review of the state-of-the-art," Renewable \& Sustainable Energy Reviews, vol. 14, no. 5, pp. 1353-1366, 2010.

[6] H. Mori and Y. Yamada, "An efficient multi-objective meta-heuristic method for distribution network expansion planning", IEEE Lausanne Powertech, vol. 1-5, pp. 374-379, 2007.

[7] E. Zitzler, M. Laumannsm, and L. Thiele, "Improving the Strength Pareto Evolutionary Algorithm," Swiss Federal Institute of Technology (ETH) Zurich, TIK-Report 103, 2001.

[8] B. Kuri, M. A. Redfern, and F. Li, "optimization of rating and positioning of dispersed generation with minimum network disruption," 2004 IEEE Power Engineering Society General Meeting, vol. 1 and 2, pp. 2074-2078, 2004.

[9] R. D. Zimmerman, C. E. Murillo-Snchez, and R. J. Thomas, "MATPOWER's Extensible Optimal Power Flow Architecture," Power and Energy Society General Meeting, 2009 IEEE, pp. 1-7, July 26-30 2009.

[10] IEEE 14 Bus System, [Online] available at: http://www.ee.washington. edu/research/pstca/pf14/pg \_tca14bus.htm, 2012.

[11] A. D. Alarcon-Rodriguez, "A multi-objective planning framework for analysing the integration of distributed energy resources." $\mathrm{PhD}$ Doctoral Thesis, University of Strathclyde, Glasgow, 2009.

[12] DEFRA, "Guidelines to DEFRA's GHG Conversion Factors (Annexes updated April 2008)," Available at: http://www.defra.gov.uk/environment/ business/envrp/pdf/ghg-cf-guidelinesannexes2008.pdf, 2008.

[13] N. Jenkins, R. Allan, P. Crossley, D. Kirschen, and G. Strbac, Embedded generation, Institution of Electrical Engineers, 2000.

[14] DECC, "Estimated emissions reduction from packaged CHP," Department of Energy \& Climate Change, Available at: http://chp.decc.gov.uk/ cms/emissions-reductions/, 2011.

[15] B. M. Weedy and B. J. Cory, Electric power systems, Wiley Publications, 1998, ISBN 9780471976776.

[16] ofgem, "FIT payment rate," [Online] available: http://www.ofgem.gov. uk/Pages/MoreInformation. aspx? docid=30 $\backslash \&$ refer=SUSTAINABILITY/ ENVIRONMENT/FITS, Accessed: 2011.

[17] K. Sameh, K. Mena, S. M. Ieee, A. C. i. Claudio, S. Ieee, and A. Member, "Modeling and simulation of IEEE 14 bus system with facts controllers," University of Waterloo, E\&CE Department, Tech. Rep. 2003-03, [Online] Available at https://ece.uwaterloo.ca/ ccanizar/papers/ IEEEBenchmarkTFreport.pdf, 2009.

[18] Y. A. Katsigiannis and P. S. Georgilakis, "A multiobjective evolutionary algorithm approach for the optimum economic and environmental performance of an off-grid power system containing renewable energy sources," Journal of Optoelectronics and Advanced Materials, vol. 10, no. 5, pp. 1233-1240, 2008
[19] BRECSU, "Small-scale combined heat \& power for buildings," UK: Building Research Energy Conservation Support Unit, Good Practice Guide 176, 1996

[20] S. R. Allen and G. P. Hammond, "Thermodynamic and carbon analyses of micro-generators for UK households," Energy, vol. 35, no. 5, pp. 22232234, 2010.

[21] Melovic, D. and Strbac, F., "Statistical Model for Design of Distribution Network", IEEE Power Tech Conference, Bologna, Italy, June 2003.

[22] A. S. Siddiqui, R. M. Firestone, S. Ghosh, M. Stadler, J. L. Edwards, and C. Marnay, "Distributed energy resources customer adoption modeling with combined heat and power applications," Lawrence Berkeley National Laboratory, 2003.

[23] DECC, "Estimated emissions reduction from packaged CHP," Department of Energy \& Climate Change, [Online] available: http://chp.decc. gov.uk/cms/emissions-reductions/, 2011.

[24] ARUP, "Review of the generation costs and deployment potential of renewable electricity technologies in the UK," Study Report submitted to Department of Energy and Climate Change (DECC), Oct 2011.

[25] AEA, "The Impacts of Distributed Generation on the Wider UK Energy System Extension of the Project," Final Report to C.E.O.S.A., DEFRA, AEA Energy and Environmental, April 2008.

[26] CumminsPower, "Generator set data sheet," [Online] available: http://www.cumminspower.com/www/common/templatehtml/ technicaldocument/SpecSheets/Diesel/na/d-3425.pdf, 2008, Accessed: 2012.

[27] Element Energy, "The growth potential for Microgeneration in England, Wales and Scotland", Final Appendix, [Online] available: http://webarchive.nationalarchives.gov.uk/+/http://www.berr.gov.uk/ files/file46421.pdf, Accessed: 2012.

[28] J. M. Fogarty, "Connections between generator specifications and fundamental design principles," in Electric Machines and Drives Conference, 2001. IEMDC 2001. IEEE International 2001, pp. 51-56.

Keshav Pokharel received BScEng (Electrical and Electronics) from Bangladesh Institute of Technology, Khulna and MEng (Energy Planning and Policy) from Asian Institute of Technology, Bangkok in 1992 and 1995 respectively. After working in various engineering and alternate energy disciplines for a significant period, he is currently perusing $\mathrm{PhD}$ in Energy and Power Management in the University of Central Lancashire, Preston, UK.

Maizura Mokhtar graduated with BEng (Hons) in Electronics and Computing from Nottingham Trent University, MSc in Control Systems from University of Sheffield and $\mathrm{PhD}$ in Electronics from University of York. She has previously worked as a Research Associate in the Department of Electronics, University of York. She is currently working as a Post Doctoral Research Assistant in the School of Computing, Engineering and Physical Sciences, University of Central Lancashire (UCLan), researching in the integration of intelligence to (energy) systems. Her research interests are artificial intelligence, bio-inspired controls and systems, intelligent systems.

Joe Howe is the University of Central Lancashire (UCLan) Professor of Sustainable Development. At UCLan, he is also the director of the Centre for Energy and Power Management, a part of School of Computing, Engineering and Physical Sciences. 